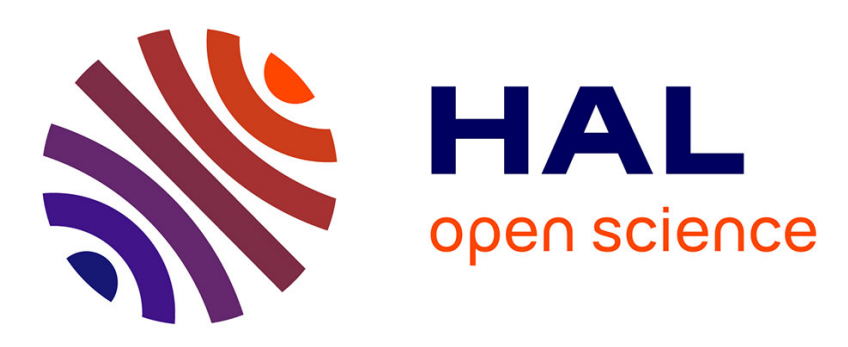

\title{
The neural basis of effective memory therapy in a patient with limbic encephalitis
}

Emma L Berry, Adam Hampshire, James Rowe, Steve Hodges, Narinder

Kapur, Peter Watson, Georgina Browne, Gavin Smyth, Ken Wood, Adrian M

Owen

\section{To cite this version:}

Emma L Berry, Adam Hampshire, James Rowe, Steve Hodges, Narinder Kapur, et al.. The neural basis of effective memory therapy in a patient with limbic encephalitis. Journal of Neurology, Neurosurgery and Psychiatry, 2009, 80 (11), pp.1202. 10.1136/jnnp.2008.164251 . hal-00552733

\section{HAL Id: hal-00552733 https://hal.science/hal-00552733}

Submitted on 6 Jan 2011

HAL is a multi-disciplinary open access archive for the deposit and dissemination of scientific research documents, whether they are published or not. The documents may come from teaching and research institutions in France or abroad, or from public or private research centers.
L'archive ouverte pluridisciplinaire HAL, est destinée au dépôt et à la diffusion de documents scientifiques de niveau recherche, publiés ou non, émanant des établissements d'enseignement et de recherche français ou étrangers, des laboratoires publics ou privés. 
The neural basis of effective memory therapy in a patient with limbic encephalitis

Corresponding Author:

Emma Berry

Microsoft Research, Cambridge

$7 \mathrm{JJ}$ Thompson Avenue

Cambridge CB3 OFB

United Kingdom

v-emmabe@microsoft.com

Telephone: +44 1223479700

Fax: +44 1223479999

Co Authors:

Adam Hampshire

MRC Cognition and Brain Science Unit

15 Chaucer Road

Cambridge

CB2 7EF

United Kingdom

adam.hampshire@mrc-cbu.cam.ac.uk

Telephone: +44 1223355294

Fax: +44 1223359062

James Rowe

MRC Cognition and Brain Science Unit

15 Chaucer Road

Cambridge

CB2 7EF

United Kingdom

james.rowe@mrc-cbu.cam.ac.uk

Telephone: +44 1223355294

Fax: +44 1223359062

Steve Hodges

Microsoft Research, Cambridge

$7 \mathrm{JJ}$ Thompson Avenue

Cambridge CB3 OFB

United Kingdom

steve.hodges@microsoft.com

Telephone: +44 1223479700

Fax: +44 1223479999
Narinder Kapur

R3 Neurosciences, Box 83

Addenbrooke's Hospital

Cambridge

CB2 0QQ

England

narinder.kapur@addenbrookes.nhs.uk

Tel. +44 1223216040

Fax - +44 1223217909

Peter Watson

MRC Cognition and Brain Science Unit

15 Chaucer Road

Cambridge

CB2 7EF

United Kingdom

peter.watson@mrc-cbu.cam.ac.uk

Telephone: +44 1223355294

Fax: +44 1223359062

Georgina Browne

Microsoft Research, Cambridge

7JJ Thompson Avenue

Cambridge CB3 OFB

United Kingdom

v-gebrow@microsoft.com

Telephone: +44 1223479700

Fax: +44 1223479999

Gavin Smyth

Microsoft Research, Cambridge

$7 \mathrm{JJ}$ Thompson Avenue

Cambridge CB3 OFB

United Kingdom

gavin.smyth@microsoft.com

Telephone: +44 1223479700

Fax: +44 1223479999

Ken Wood

Microsoft Research, Cambridge

$7 \mathrm{JJ}$ Thompson Avenue

Cambridge CB3 OFB

United Kingdom

ken.wood@microsoft.com

Telephone: +44 1223479700

Fax: +44 1223479999 
Adrian M. Owen

MRC Cognition and Brain Science Unit

15 Chaucer Road

CambridgeCB2 7EF

United Kingdom

adrian.owen@mrc-cbu.cam.ac.uk

Telephone: +44 1223355294

Fax: +44 1223359062

Key Words = AMNESIA; FUNCTIONAL IMAGING; LIMBIC SYSTEM; MEMORY; REHABILITATION

Word Count $=1577$ 


\section{ABSTRACT}

We describe an fMRI study in which a post-encephalitic woman with amnesia, 'Mrs B', used a wearable camera which takes photographs passively, without user intervention, to record and review recent autobiographical events. 'SenseCam' generates hundreds of images which can subsequently be reviewed quickly or one-by-one. Memory for a significant event was improved substantially when tested after 4.5 weeks, if Mrs B viewed SenseCam images of the event every two days for three weeks. In contrast, after only 3.5 weeks, her memory was at chance levels for a similarly significant event which was reviewed equally often, but using a written diary. During the fMRI scan, Mrs B viewed images of these two events, plus images of an unrehearsed event and images from a novel 'control' event that she had never experienced. There was no difference in behavioural responses or in activation when the unrehearsed and novel conditions were compared. Relative to the written-rehearsed condition, successful recognition of the images in the SenseCam-rehearsed condition was associated with activation of frontal and posterior cortical regions associated with normal episodic memory. We conclude that SenseCam images may provide powerful cues that trigger the recall and consolidation of stored but inaccessible memories.

\section{INTRODUCTION}

Memory problems after limbic encephalitis are common [1]. Patients often have severe deficits in the learning and retention of new information and in remembering past events. Recently a case has been described of a woman with amnesia following limbic encephalitis whose memory for recent events dramatically improved through the use of a wearable camera, which enabled her to systematically review past autobiographical events [2]. However, the neural basis of this memory improvement remains unknown. We report the results of an fMRI study in which the same procedure was used to monitor memory improvements in the same woman.

\section{CASE REPORT}

Mrs B is a 66-year-old, right-handed librarian. In March 2002 she was diagnosed with limbic encephalitis on the basis of clinical syndrome, MRI and examination of cerebrospinal fluid. Anti-voltage gated potassium channel antibodies were negative in serum and CSF. An MRI scan in 2005 showed a mild degree of volume loss in the hippocampi but that the signal change present acutely had resolved. Severe cognitive deficits were apparent on neuropsychological testing one and three years later. She exhibited marked anterograde memory impairment and mild to moderate retrograde memory impairment. Other cognitive functions were intact (see Table 1) [2]. See supplementary clinical details.

Table 1: Neuropsychological test results for Mrs B (April 2003 to March 2005)

\begin{tabular}{|l|l|l|l|}
\hline Test & Raw score & $\begin{array}{l}\text { Scaled score or } \\
\text { percentile (where appropriate) }\end{array}$ & Comments \\
\hline $\begin{array}{l}\text { Estimate of premorbid } \\
\text { cognitive } \\
\text { functioning }\end{array}$ & & & \\
\hline $\begin{array}{l}\text { National Adult Reading } \\
\text { Test }\end{array}$ & 13 errors & $\begin{array}{l}\text { Predicted } \\
\text { FSIQ }=115\end{array}$ & $\begin{array}{l}\text { Above average } \\
\text { estimated } \\
\text { premorbid cognitive } \\
\text { functioning }\end{array}$ \\
\hline $\begin{array}{l}\text { Memory } \\
\text { Meors and People }\end{array}$ & All tests & 1 st-5th percentile & \\
\hline $\begin{array}{l}\text { Autobiographical } \\
\text { Memory Interview : All }\end{array}$ & & & \\
\hline
\end{tabular}




\begin{tabular}{|c|c|c|c|}
\hline \multicolumn{4}{|l|}{ tests } \\
\hline $\begin{array}{l}\text { Childhood Personal } \\
\text { Semantic }\end{array}$ & $18 / 21$ & & Acceptable range \\
\hline $\begin{array}{l}\text { Childhood } \\
\text { Autobiographical } \\
\text { Incidents }\end{array}$ & $2 / 9$ & & Definitely abnormal \\
\hline $\begin{array}{l}\text { Early Adult Life Personal } \\
\text { Semantic }\end{array}$ & $15 / 21$ & & Probably abnormal \\
\hline $\begin{array}{l}\text { Early Adult Life } \\
\text { Autobiographical } \\
\text { Incidents }\end{array}$ & $3 / 9$ & & Definitely abnormal \\
\hline $\begin{array}{l}\text { Recent Life Personal } \\
\text { Semantic }\end{array}$ & $15 / 21$ & & Definitely abnormal \\
\hline $\begin{array}{l}\text { Recent Life } \\
\text { Autobiographical } \\
\text { Incidents }\end{array}$ & $3 / 9$ & & Definitely abnormal \\
\hline \multicolumn{4}{|l|}{ Language } \\
\hline $\begin{array}{l}\text { Pyramids and Palm } \\
\text { Trees }\end{array}$ & $51 / 52$ & & Within normal limits \\
\hline Graded Naming Test & $22 / 30$ & 75th percentile & Within normal limits \\
\hline \multicolumn{4}{|l|}{ Attention } \\
\hline $\begin{array}{l}\text { TEA: Lottery and Map } \\
\text { Search }\end{array}$ & & & Within normal limits \\
\hline WAIS-III Digit Span & 22 & $\mathrm{SS}=14$ & Within normal limits \\
\hline \multicolumn{4}{|l|}{ Executive Function } \\
\hline Hayling & 15 & $S S=5$ & Moderate average \\
\hline Brixton & 13 errors & $\mathrm{SS}=7$ & High Average \\
\hline $\begin{array}{l}\text { Behavioural Assessment } \\
\text { of the } \\
\text { Dysexecutive } \\
\text { Syndrome: All tests }\end{array}$ & & & Within normal limits \\
\hline \multicolumn{4}{|l|}{$\begin{array}{l}\text { Visuo-Perceptual } \\
\text { Functioning }\end{array}$} \\
\hline $\begin{array}{l}\text { Visual Object Space } \\
\text { Perception } \\
\text { Battery: All tests }\end{array}$ & Pass & & Within normal limits \\
\hline Benton Line Orientation & $27 / 30$ & & Within normal limits \\
\hline $\begin{array}{l}\text { AMIPB Complex Figure } \\
\text { Copy }\end{array}$ & 64 & 90th percentile & Within normal limits \\
\hline
\end{tabular}

In 2006, her memory for recent events remained severely impaired [2]. However, intervention in the form of a camera, known as 'SenseCam' (Microsoft Research, Cambridge) led to a dramatic improvement in her memory for reviewed events [2]. Mrs B had an episodic recollection of the events and described occurrences, thoughts and feelings not captured by the images. A control condition using a written diary did not cue recall to the same extent and, without ongoing rehearsal, the events were quickly forgotten. However, the study gave no insight into the neural basis of her improved autobiographical memory.

\section{METHOD}

\section{SenseCam}

SenseCam is a wearable camera which passively takes photographs approximately every thirty seconds and in response to various sensors such as light and movement [3]. Over the course of a day, hundreds of images are generated which can be uploaded onto a computer 
via USB and played back in quick succession using a simple interface. The effect is rather like watching a movie of the day's events. In the study by Berry et al. (2007) [2] Mrs B wore the camera during significant and memorable events (e.g. a trip to London or the theatre - i.e. not the mundane or routine) and subsequently reviewed the images approximately every two days for two weeks. The images cued her recall for the events, and after the initial rehearsal period, she retained memories for the events months later, without the need to re-review the images.

\section{Stimulus Preparation}

In 2007, Mrs B underwent fMRI under four conditions. In preparation for the first three conditions, SenseCam images were collected from three separate two-day trips made by Mrs B during the previous six weeks. Specifically, Mr and Mrs B went on a significant, memorable trip, staying in a hotel overnight in a town they had not visited previously or for many years. Mrs B wore SenseCam throughout. In preparation for condition 1 (henceforth referred to as 'Not Reviewed') Mr and Mrs B went away 6.5 weeks prior to the fMRI scan, and afterwards they did not view the images or talk about the trip. For condition 2 ('SenseCam'), Mr and Mrs B went away on a trip 4.5 weeks before the scan, and afterwards $\mathrm{Mr}$ and Mrs B viewed the SenseCam images approximately every two days for three weeks until one week prior to the scan. For condition 3 ('Written') Mr and Mrs B went on a trip 3.5 weeks prior to the scan and $\mathrm{Mr} B$ recorded details of the event using a written diary. Mr and Mrs $B$ viewed and talked through the written diary every two days for three weeks, up until the scan took place. In condition 4 ('Novel'), one of the authors (AMO) wore SenseCam to collect images of an objectively comparable trip.

\section{Procedure}

Whilst in the fMRI scanner, Mrs B viewed a series of 150 SenseCam images. She indicated, using a button box, whether or not she definitely recognised the viewed picture (henceforth referred to as 'known'), felt that it was familiar but did not have explicit recall or recognition of the event ('familiar') or did not recognise the picture ('not known').

\section{See supplementary methods}

\section{RESULTS}

\section{Behavioural Data}

When the Novel stimuli were compared with the Not Reviewed stimuli, there were no significant differences. When Sensecam images were compared with Written images, significant differences were found (chi-square $(1)=23.26, p<0.001$ ). Specifically, there was a larger total proportion of images that were rated as known or familiar in the SenseCam condition than in the Written condition. Thus the behavioural efficacy of SenseCam [2] can be reproduced even in the scanning environment (see Figure 1a).

\section{Imaging Data}

In the first comparison, Novel and the Not Reviewed conditions were compared directly. No significance differences were observed using a conservative threshold of $p<0.05$ false discovery rate corrected (FDR) for the whole brain mass.

Next, brain activity during the two reviewed conditions (SenseCam vs. Written) was compared. Significant differences were observed across a network of brain including the left ventrolateral prefrontal cortex $(-18,10,-18 ;-38,40,-14)$, the right frontal pole $(20,64,28)$, the posterior temporal lobe bilaterally (Left inferior temporal gyrus -44, -62, -10; Right inferior temporal gyrus 52, $-70,-6$; Right middle temporal gyrus 56, $-62,-2$ ), bilateral parietal 
cortex (Left -64, -34, 24; Right 56, -52, 40), bilateral visual association cortex (Left inferior occipital gyrus $-42-68-14$; Right inferior occipital gyrus 56, -66, -10) and the left fusiform gyrus $(-40,-56,-14)$ (see supplementary figure 51 ).

Performance differences confound the activation differences, making interpretation of the fMRI ambiguous. To address this, only the remembered stimuli ('known' plus 'familiar') from the two conditions were compared. Importantly, the proportion of 'known' to 'familiar' stimuli within each condition was similar. Because the power to detect significant differences was lower given the $33 \%$ reduction in the number of responses for this analysis, a liberal $p<0.005$ uncorrected threshold was used. Consequently, a very similar pattern of differences was observed to the original SenseCam vs. Written comparison, suggesting that even when the behavioural responses are the same between conditions, activation differences remain (see Figure $1 \mathrm{~b}$ ).

\section{See supplementary results.}

\section{DISCUSSION}

There were no significant differences in the patient's behavioural or fMRI responses to Novel images and images of personally experienced events she had not reviewed. She did not recognise the images in either condition. Her amnesic syndrome remains severe, confirming the findings of our previous study [2].

When the SenseCam and Written conditions were compared, there were significant behavioural and fMRI differences. She recognised, or was familiar with, more of the images in the SenseCam than in the Written condition, supporting previous results [2]. As the SenseCam condition occurred one week before the Written condition, it cannot be argued that better recognition resulted because the event was more recent. When Mrs B's BOLD response to images in the SenseCam and Written conditions were compared, increases in activation were observed in a cortical network, including the left ventrolateral prefrontal cortex, frontal pole (area 10), posterior temporal cortex, parietal cortex, visual association cortex bilaterally and fusiform gyrus. These differences remained when only the remembered stimuli (known plus familiar) from the two conditions were compared, demonstrating that even when the behavioural responses were formally matched, the activity associated with the recollection in the two conditions was different.

Importantly, we cannot be certain that the neural activity associated with viewing the images in the SenseCam condition reflected memory for the event itself, rather than memory for the images themselves or memory of reviewing those images. These possibilities can only be discounted by additional control conditions which should be considered in future studies. However, Mrs B maintains that the images effect a natural recollection, suggesting that SenseCam images provide powerful cues that allow access to stored but unattainable memories.

The study of autobiographical memory processes using functional imaging techniques poses challenges in study design and interpretation (see 4, for a review). However, our results concur with previous evidence linking autobiographical memory to a network of prefrontal regions involved in effortful processing and posterior regions where such memories are stored [4-11]. The frontal regions activated in our study have been associated with selfreferential processing, memory retrieval, 'feelings of rightness' [5, 8-10] and source memory (area 10) which, arguably, is a central feature of autobiographical retrieval [12]. 
The importance of the hippocampus for long-term episodic memory formation is well documented [13-14]. However in our patient, the hippocampal system was affected acutely and we observed no medial temporal lobe activation. And yet, she appears to have significant memory for the events reviewed using SenseCam. We hypothesise that SenseCam may improve performance by providing a bottom-up replacement for the medial temporal lobes. SenseCam images may provide such a powerful cue that reviewing them is sufficient to reinforce consolidation of the episode into a retrievable long term memory store. By contrast, a written diary does not provide powerful enough cues to overcome the hippocampal deficit.

\section{CONCLUSION}

Using SenseCam provides subjective and objective improvements in autobiographical memory for reviewed events, even when a post-encephalitic amnesic syndrome is severe. This is associated with activation of frontal and posterior cortical regions but not the hippocampus. A larger group study should be undertaken before strong conclusions about the benefits of this intervention and its role in autobiographical memory are drawn. 


\section{ACKNOWLEDGMENTS}

The authors would like to thank Mrs B for kindly agreeing to participate in the study and Mr $B$ for his great help in carrying out the experiment. They also very much appreciate Professor Roberto Cabeza's advice regarding the experimental design. AMO and AH are supported by the Medical Research Council U1055.01.002.00001.01.

\section{COMPETING INTERESTS}

Emma Berry and Georgina Browne receive consultancy fees from Microsoft Research, Cambridge. Narinder Kapur receives grant support and consultancy fees from Microsoft Research, Cambridge.

\section{FUNDING}

Microsoft Research Ltd, Roger Needham Building, JJ Thomson Avenue, Cambridge CB3 OFB. 


\section{References}

1 Hokkanen L \& Launes J. Neuropsychological sequelae of acute-onset sporadic viral encephalitis. Neuropsychol Rehabil 2007;17,4/5:450-477.

2 Berry E, Kapur N, Williams L, Hodges S, Watson P, Smyth, G, Srinivasan, J, Smith R, Wilson B \& Wood K. The use of a wearable camera, SenseCam, as a pictorial diary to improve autobiographical memory in a patient with limbic encephalitis. Neuropsychol Rehabil 2007;17:4/5: 582-681.

3 Hodges S, Williams L, Berry E, Izadi S, Srinivasan J, Butler A, Smyth G, Kapur N \& Wood K. SenseCam: a Retrospective Memory Aid. In: Dourish P, Friday A, eds. UbiComp 2008: Ubiquitous Computing. Heidelberg: Springer-Verlag 2008;4206:177-193.

4 Cabeza R, \& St. Jacques, P. L. Functional neuroimaging of autobiographical memory. Trends in Cognitive Sciences 2007;11:219-227.

5 Conway M.A. Memory and the Self. J Mem Lang 2005;53:4:594-628.

6 Conway M.A \& Pleydell-Pearce C.W. The construction of autobiographical memories in the self memory system. Psychol Rev 2000;107:261-288.

7 Botzung A, Denkova E, Ciuciu P, Scheiber C, \& Manning L. The neural bases of the constructive nature of autobiographical memories studied with a self-paced fMRI design. Memory 2008;16:4:351-363.

8 Burianova H. \& Grady C.L. Common and unique neural activations in autobiographical, episodic, and semantic retrieval, J Cogn Neurosci 2007;19:9:1520-34.

9 Levine B, Turner G.R, Tisserand D, Hevenor S.J, Graham S.J \& McIntosh A.R. The functional neuroanatomy of episodic and semantic autobiographical remembering: a prospective functional MRI study. J Cogn Neurosci 2004;16:9:1633-1646.

10 Svoboda E, McKinnon M.C, \& Levine B. The functional neuroanatomy of autobiographical memory: a meta-analysis. Neuropsychologia 2006;44:12:2189-2208.

11 Vandekerckhove M.M, Markowitsch H.J, Mertens M, Woermann, F.G. Bi-hemispheric engagement in the retrieval of autobiographical episodes. Behav Neurol 2005;16:4:203-210.

12 Ramnani N \& Owen A.M. Anterior Prefrontal Cortex: insights into function from anatomy and neuroimaging. Nature Reviews Neuroscience 2004;5:3:184-194.

13 Squire L.R. Memory and the hippocampus: A synthesis from findings with rats, monkeys and humans. Psychological Review 1992;99:2:195-231.

14 Nadel L, Samsonovich A, Ryan L \& Moscovitch M. Multiple trace theory of human memory: computational, neuroimaging, and neuropsychological results. Hippocampus 2000;10:4:352-368. 
The Corresponding Author has the right to grant on behalf of all authors and does grant on behalf of all authors, an exclusive licence (or non-exclusive for government employees) on a worldwide basis to the BMJ Publishing Group Ltd and its Licensees to permit this article (if accepted) to be published in Journal of Neurology, Neurosurgery \& Psychiatry and any other BMJPGL products to exploit all subsidiary rights, as set out in our licence (http://jnnp.bmj.com/ifora/licence.pdf). 
A

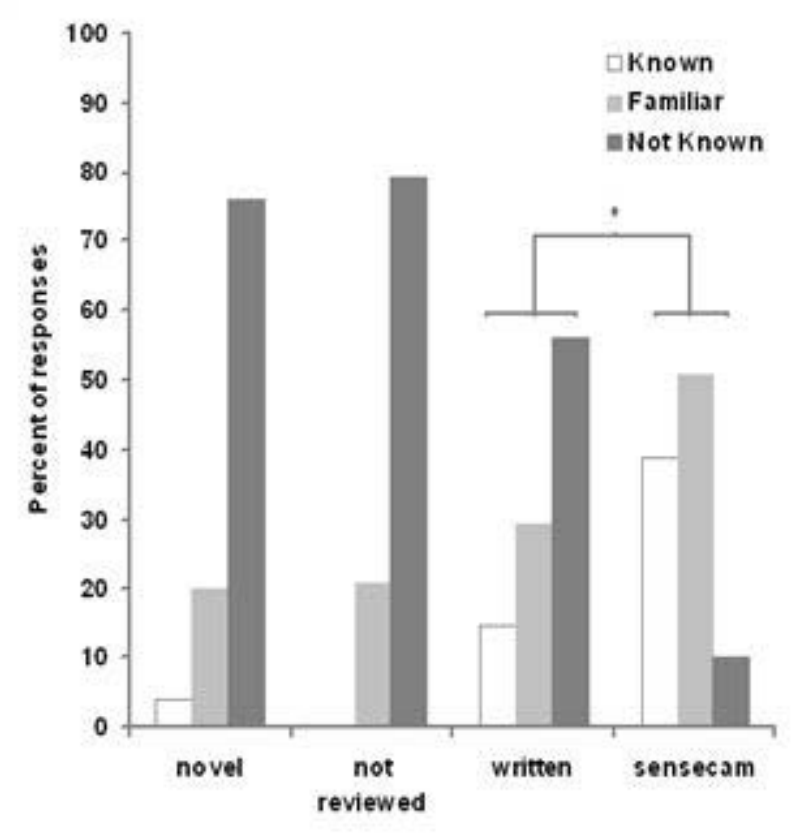

B

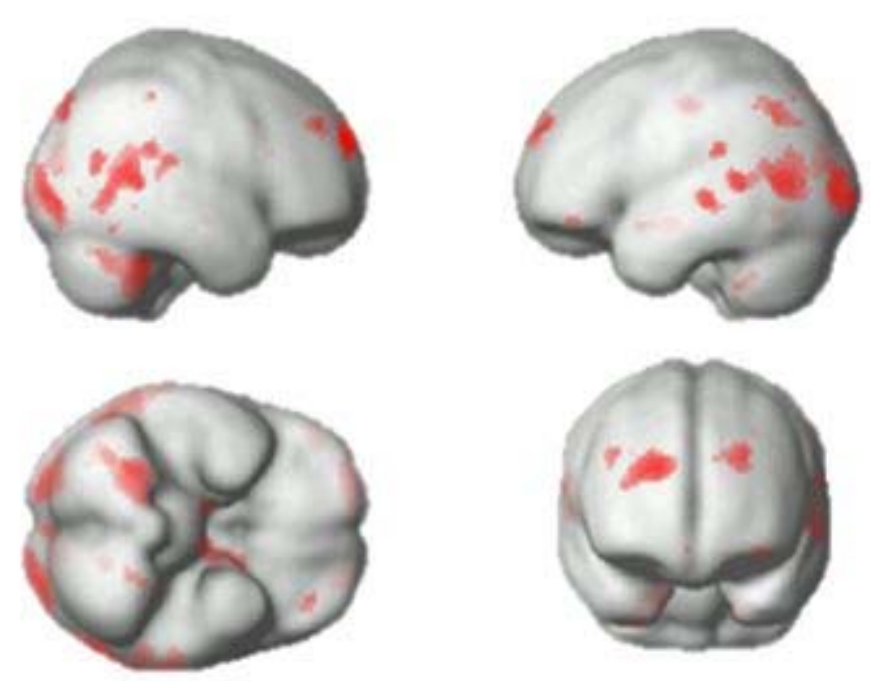

